\title{
Sintering of Silicon Carbide and Theory of Sintering
}

\author{
Hidehiko TANAKA \\ Advanced Materials Laboratory, National Institute for Materials Science, 1-1, Namiki, Tsukuba-shi, Ibaraki \\ 305-0044
}

\author{
炭化ケイ素の焼結と焼結理論に関する研究 \\ 田中英彦 \\ 物質・材料研究機構物質研究所, 305-0044 つくば市並木 1-1
}

\begin{abstract}
The three important aspects of sintering of SiC, that is, powder processing, sintering additives and sintering theory, are reviewed in this paper. First, in order to obtain sinterable SiC powder, the carbothermic reduction of $\mathrm{SiO}_{2}$ was investigated using a precursor derived from liquid sources. $\beta(3 \mathrm{C})-\mathrm{SiC}$ powder free from any residual carbon was synthesized. The powder did not need a purification process and could be sintered with $\mathrm{C}$ and a small amount of $\mathrm{B}$ additives. Second, low-temperature sintering of $\alpha(6 \mathrm{H})-\mathrm{SiC}$ powder by $\mathrm{AlB}_{2}$ and $\mathrm{C}$ additives was developed. $\mathrm{AlB}_{2}$ addition enabled the sintering of $\mathrm{SiC}$ powder at around $1900^{\circ} \mathrm{C} . \mathrm{Al}$ atoms from the additives dissolved into $\mathrm{SiC}$ and promoted elongation of grains during sintering. The fracture toughness of sintered $\mathrm{SiC}$ increased with the aspect ratio of the grains. Third, to understand the sintering behavior of $\mathrm{SiC}$ powder, new sintering models and a theory were proposed. In the theory, it was assumed that total excess energy in a system drove mass transport for sintering and grain growth. From the rate equations of sintering and grain growth, the surface energy and the grain boundary energy were found to play an important role in both processes.

[Received April 24, 2002]
\end{abstract}

Key-words : Silicon carbide, Powder synthesis, Organic source, Low-temperature sintering, Aluminum boride additive, Sintering theory, Grain growth theory, Free energy, Diffusion path

1. Introduction

$\mathbf{S}^{1}$ LICON carbide $(\mathrm{SiC})$ ceramics are one of the most important engineering ceramics in the industry. They have good anticorrosive and superior tribological properties in addition to exhibiting high strength at high temperatures. They are widely applied in mechanical parts, such as mechanical seals, furnace substrates, high temperature parts and so on. ${ }^{1), 2)}$ The high covalent bonding nature of SiC requires a very high temperature and suitable additives for sintering. ${ }^{1)}$ The key points in the fabrication of high-density $\mathrm{SiC}$ materials are to obtain fine sinterable $\mathrm{SiC}$ powders and to find effective additives. Establishment of the basic theory on sintering is also important in the production of high-performance SiC materials. ${ }^{2)}$

In this paper, three key aspects of $\mathrm{SiC}$ materials are summarized, that is, the novel method of fabricating fine $\mathrm{SiC}$ powder, ${ }^{3), 4)}$ the sintering process with the new additive ${ }^{5), 6)}$ and the new sintering theory applicable to the processing of $\mathrm{SiC}$ materials. ${ }^{7), 8)}$

The powder characteristics are very important when fabricating sintered $\mathrm{SiC}$. The most important characteristics are fine grain size, high purity and mono-phase crystal. In the industry, SiC powder is synthesized by the Acheson process or by carbothermic reduction of $\mathrm{SiO}_{2}$ grains. The former process produces $\alpha(6 \mathrm{H})$-SiC crystals and $\mathrm{SiC}$ powder is obtained through pulverization and purification processes. The latter process produces $\beta(3 \mathrm{C})-\mathrm{SiC}$ powder from $\mathrm{SiO}_{2}$ and $\mathrm{C}$ powders. In this process, it is important to mix raw materials, because the carbothermic reduction of $\mathrm{SiO}_{2}$ is a typical solid-state heterogeneous reaction. The synthesized powder requires a purification process to remove carbon residue.

This paper first describes the new process of $\mathrm{SiC}$ powder synthesis and sinterability of the powder. The author examined inorganic liquids as sources for $\mathrm{SiO}_{2}$ and $\mathrm{C}$ to achieve fine mixing of raw materials. By polymerization and carbonization of these materials, a precursor consisting of $\mathrm{SiO}_{2}$ and $\mathrm{C}$ was obtained and was converted into fine and sintera- ble $\mathrm{SiC}$ powder. The powder was of pure $\beta$-SiC free from any residual carbon.

Second, the sintering of $\mathrm{SiC}$ powder using new additives of $\mathrm{AlB}_{2}$ and $\mathrm{C}$ is described. Pressureless sintering of $\mathrm{SiC}$ by the addition of $\mathrm{B}$ and $\mathrm{C}$ was first reported by Prochazka. ${ }^{9}$ ) This method has become an important technology in the manufacturing of SiC materials. There are, however, still some problems with this process, i.e., the high sintering temperature of $\sim 2150^{\circ} \mathrm{C}^{10}$ ) and low toughness of the materials. ${ }^{11), 12)}$ The author had intensively investigated the sintering process of $\mathrm{SiC}$ materials. ${ }^{13), 14)} \mathrm{He}$ found that $\mathrm{AlB}_{2}$ and $\mathrm{C}$ were very effective additives. ${ }^{5), 6)}$ These additives reduced the sintering temperature significantly and enhanced rod- or plate-shaped grain growth, which was expected to increase the fracture toughness of the materials.

Another important point in the sintering of $\mathrm{SiC}$ is to establish the sintering theory for the covalent bonding materials, such as $\mathrm{SiC}$ and $\mathrm{Si}_{3} \mathrm{~N}_{4}$, which require additives for sintering. ${ }^{13), 15)}$ The additives are thought to precipitate at the grain boundary, 16),17) promote sintering and control grain growth by decreasing grain boundary energy. One of the most important requirements for sintering $\mathrm{SiC}$ powder is to find suitable additives which can decrease grain boundary energy. ${ }^{1)}$

Third, the new sintering and grain growth theories are described in this paper. There has been much work performed to date on the theory of sintering ${ }^{18)-24)}$ and grain growth. ${ }^{23), 25)-28)}$ The traditional theories of sintering are based on the two contacting grains models. They assume that the difference in chemical potential due to the curvatures between the neck and grain surface drove mass transport. The theories can not explain directly the role of grain boundary energy on sintering and grain growth. A new sintering theory was required for the $\mathrm{SiC}$ materials. The new theory adopts the two-sphere models where two grains join at a planar grain boundary without neck curvature. The sintering proceeds by expansion of the grain boundary and grain growth proceeds by mass transport through the boun- 
dary. Excess energy on the surface and at the grain boundary is assumed to drive mass transport. From the model, the rate equations for sintering and grain growth are derived, and the role of grain boundary energy on the sintering is discussed.

\section{Synthesis of SiC powder and its sinterability}

\section{1 $\mathrm{SiC}$ precursor from liquid raw materials}

Silicon-tetraethoxide $\left(\left(\mathrm{C}_{2} \mathrm{H}_{5} \mathrm{O}\right)_{4} \mathrm{Si}\left(\mathrm{OSi}_{(}\left(\mathrm{OC}_{2} \mathrm{H}_{5}\right)_{2}\right)_{n}\right)$ and phenolic resin were used for fine mixing of $\mathrm{SiO}_{2}$ and $\mathrm{C}$ in a liquid phase. The mixtures of these materials with a suitable amount of water were stirred and polymerized. The polymers were dried and heated at $1000^{\circ} \mathrm{C}$. Homogeneous glossy black $\mathrm{SiC}$ precursors were obtained. The precursors were glass-like solids, and $\mathrm{SiO}_{2}$ and $\mathrm{C}$ components did not separate. The X-ray diffraction and IR analyses revealed that the precursors were amorphous and consisted of $\mathrm{SiO}_{2}$ and $\mathrm{C}$. The molar ratios of $\mathrm{C} / \mathrm{Si}$ in the synthesized precursors were 1.7-3.1.

\subsection{Synthesis of $\mathrm{SiC}$ powder}

Fine yellow $\beta$-SiC powders were synthesized by the reaction of the precursors at $1500-1800^{\circ} \mathrm{C}$. The X-ray diffraction patterns and the SEM image of the powders are shown in Figs. 1 and 2. The reaction of $\mathrm{SiO}_{2}$ and $\mathrm{C}$ was completed at over $1600^{\circ} \mathrm{C}$. The yields of $\mathrm{SiC}$ from the precursors were 0.6-0.8 depending on the $\mathrm{C} / \mathrm{Si}$ ratio. For the $\mathrm{C} / \mathrm{Si}$ ratios of 1.7-2.5, the powder contained neither residual $\mathrm{SiO}_{2}$ nor $\mathrm{C}$, and thus required no oxidation process or acid treatment. The particle sizes of the synthesized powders were in the sub-micron range for the synthesis temperature of $1600^{\circ} \mathrm{C}$. The particle sizes increased to several microns for the synthesis temperatures of 1700 to $1800^{\circ} \mathrm{C}$.

The X-ray diffraction analysis (Fig. 1) showed that the powder synthesized at $1600^{\circ} \mathrm{C}$ was of the $\beta$ phase and contained a small amount of $2 \mathrm{H}$ phase. The powder synthesized at $1700^{\circ} \mathrm{C}$ was a pure $\beta$-SiC and had very large crystallite size $(>100 \mathrm{~nm})$.

\subsection{Sintering of $\mathrm{SiC}$ powder}

The powder synthesized at $1750^{\circ} \mathrm{C}$ from the precursor

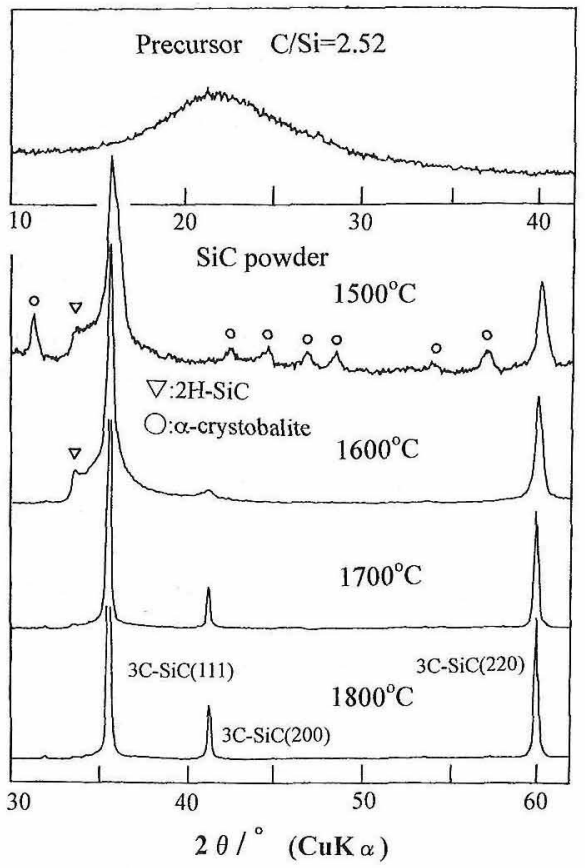

Fig. 1. X-ray diffraction patterns of the precursor and the synthesized powders.
$\mathrm{C} / \mathrm{Si}=2.52$ was pulverized and sintered by adding 0.1 1 mass\% B and 2 mass\% C. Figure 3 shows the results demonstrating high sinterability of the powder. The powder could be sintered nearly to the theoretical density with $0.2-$ 1 mass $\% \mathrm{~B}$ and 2 mass \% C. In the previous investigations of sintering of $\beta$ - $\mathrm{SiC}$ powder, about $0.5-1$ mass $\% \mathrm{~B}$ and 2 mass \% were required to achieve a high density. Figure 4 shows the SEM micrograph of the sintered SiC. The microstructure was that of typical sintered $\beta$-SiC consisting of plate- and rod-shaped grains.

The powders from the precursors required no purification processes to remove either residual carbon or $\mathrm{SiO}_{2}$, and could be sintered by the addition of $\mathrm{C}$ and a small amount of B.

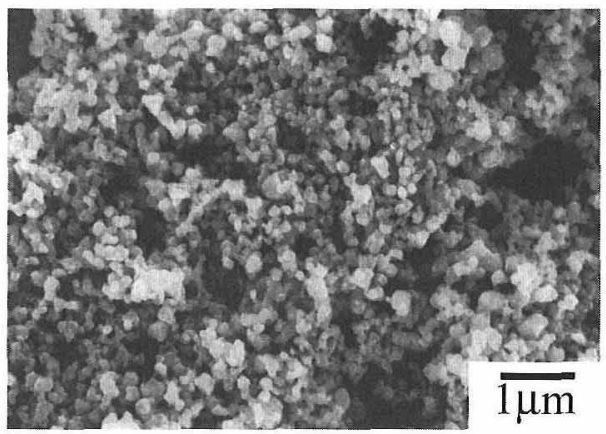

Fig. 2. Powder morphology synthesized at $1600^{\circ} \mathrm{C}$ from the precursor $\mathrm{C} / \mathrm{Si}=2.52$.

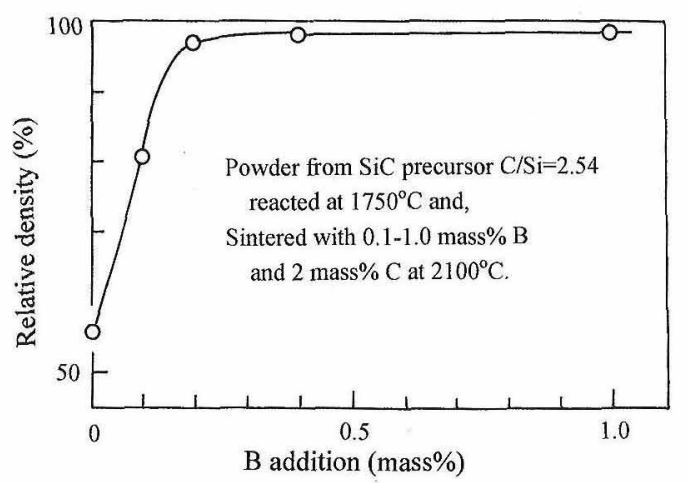

Fig. 3. Density of the $\mathrm{SiC}$ materials sintered from the powder synthesized from the precursor $\mathrm{C} / \mathrm{Si}=2.52$.

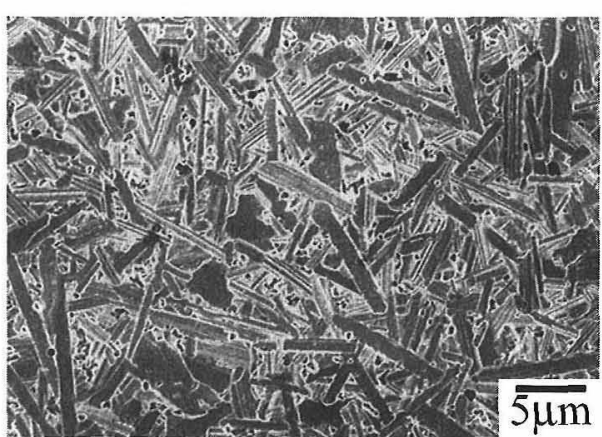

Fig. 4. Microstructure of the $\mathrm{SiC}$ material sintered at $2100^{\circ} \mathrm{C}$ with 0.2 mass $\% \mathrm{~B}$ and 2 mass $\% \mathrm{C}$. The starting powder was synthesized from the precursor $\mathrm{C} / \mathrm{Si}=2.52$ at $1750^{\circ} \mathrm{C}$. 
3. Sintering of $\mathrm{SiC}$ powder with $\mathrm{AlB}_{2}$ and $\mathrm{C}$ additives

3.1 Low-temperature sintering of $\alpha$-SiC powder by $\mathrm{AIB}_{2}$ and $\mathrm{C}$ additives

$\alpha$-SiC fine powder (mean grain size is $0.95 \mu \mathrm{m}$ ), $\mathrm{AlB}_{2}$ powder, and phenol resin (phenol formaldehyde condensate) for $\mathrm{C}$ were used as the starting material and additives. They were mixed in a SiC ball mill with ethanol medium. The contents of $\mathrm{AlB}_{2}$ and $\mathrm{C}$ additives were $0.65-5.4$ mass $\%$ and 2 mass $\%$, respectively (Table 1 ). The powders were subsequently dried, compacted by CIP at $200 \mathrm{MPa}$, and sintered in a carbon resistance furnace. The specimens were first heated up to $1500^{\circ} \mathrm{C}$ in vacuum to remove $\mathrm{SiO}_{2}$ in the $\mathrm{SiC}$ powder. They were then sintered between 1800 to $2150^{\circ} \mathrm{C}$ in $\mathrm{Ar}$ flow.

Table 1 lists the densities of the specimens sintered at various temperatures. The specimens which contained 0.67-2.7 mass $\% \mathrm{AlB}_{2}$ were sintered almost to the full density ( $>97 \%$ of TD (Theoretical density)) at a temperature as low as $1900^{\circ} \mathrm{C}$. This sintering temperature is about $250^{\circ} \mathrm{C}$ lower than that of the conventional sintering process. Sintering of $\mathrm{SiC}$ powder in the industry is usually performed with $\mathrm{B}$ and $\mathrm{C}$ additives at about $2150^{\circ} \mathrm{C}$. The specimen with 5.40 mass $\% \mathrm{AlB}_{2}$ did not sinter to the full density. Clearly exaggerated grain growth occurred at the early stage of sintering and suppressed densification of $\mathrm{SiC}$ powder.

Inomata and Tanaka ${ }^{29)}$ investigated the phase compatibility in the $\mathrm{Al}-\mathrm{B}-\mathrm{C}$ system, and found the new compound $\mathrm{Al}_{8} \mathrm{~B}_{4} \mathrm{C}_{7}$, which formed a liquid phase at $1800^{\circ} \mathrm{C}$. It was suggested that the liquid phase was formed from $\mathrm{AlB}_{2}$ and $\mathrm{C}$ and enhanced sintering at $1800-1900^{\circ} \mathrm{C}$ due to a rapid diffusion path at the grain boundary.

3.2 Phase transformation of $\alpha$-SiC and grain growth

The polytypes of $\mathrm{SiC}$ grains in the sintered materials were analyzed by the powder X-ray diffraction method. The results are listed in Table 2 . The starting powder was mostly $6 \mathrm{H}-\mathrm{SiC}$, and part of $6 \mathrm{H}-\mathrm{SiC}$ was transformed into $4 \mathrm{H}-\mathrm{SiC}$ after sintering. The transformation was particularly marked when the sintering temperature was high and when the amount of $\mathrm{AlB}_{2}$ was large. It was also observed that $\mathrm{SiC}$ grains grew aspherically in the specimens doped with a large amount of additives. Figure 5 shows sample of the microstructures of the sintered $\mathrm{SiC}$.

Polymorphism and thermal stability of $\mathrm{SiC}$ have been studied in detail. ${ }^{1), 2)}$ It has been clarified that $6 \mathrm{H}$ is stable at $2000^{\circ} \mathrm{C}$ and above. $4 \mathrm{H}$ is stable below $2000^{\circ} \mathrm{C}$, and it becomes stable if $\mathrm{Al}$ atoms dissolve into $\mathrm{SiC}$. Transforma-

Table 1. Contents of Additives in Starting Powders and Sintering Densities

\begin{tabular}{|c|c|c|c|c|c|c|}
\hline Sample & \multicolumn{6}{|c|}{ Contents of $\mathrm{AlB}_{2}, \mathrm{C}$ and $\mathrm{SiC}$ powder (mass $\%$ ) } \\
\hline No. & \multicolumn{2}{|c|}{$\mathrm{AlB}_{2}$} & \multicolumn{2}{|c|}{$\mathrm{C}$} & \multicolumn{2}{|c|}{ iC powder } \\
\hline $\mathrm{SC}-1$ & \multicolumn{2}{|c|}{0.67} & \multicolumn{2}{|c|}{2.00} & \multicolumn{2}{|c|}{97.33} \\
\hline $\mathrm{SC}-2$ & \multicolumn{2}{|c|}{1.34} & \multicolumn{2}{|c|}{2.00} & \multicolumn{2}{|c|}{96.66} \\
\hline $\mathrm{SC}-3$ & \multicolumn{2}{|c|}{2.70} & \multicolumn{2}{|c|}{2.00} & \multicolumn{2}{|c|}{95.30} \\
\hline \multirow[t]{3}{*}{$\mathrm{SC}-4$} & \multicolumn{2}{|c|}{5.40} & \multicolumn{2}{|c|}{2.00} & \multicolumn{2}{|c|}{92.60} \\
\hline & \multicolumn{6}{|c|}{ Sintering Temperatures $\left({ }^{\circ} \mathrm{C}\right)$ and densities of sintered $\mathrm{SiC}(\% \mathrm{TD}$} \\
\hline & 1800 & 1850 & 1900 & 1975 & 2000 & 2150 \\
\hline SC-1 & 87.2 & 94.6 & 98.0 & & 98.8 & $99.9^{\mathrm{G}}$ \\
\hline SC-2 & 90.7 & 96.0 & 97.2 & & 98.9 & $97.9^{\mathrm{G}}$ \\
\hline SC-3 & 90.2 & 96.5 & 97.4 & $97.8,97.6^{*}$ & & $96.7^{\mathrm{G}}$ \\
\hline $\mathrm{SC}-4$ & 79.3 & 80.2 & $81.8^{\mathrm{G}}$ & $85.4^{\mathrm{G}}$ & & $86.1^{\mathrm{G}}$ \\
\hline
\end{tabular}

Holding time at the maximum temperature is $30 \mathrm{~min}$ or $* 0 \mathrm{~min}$.

${ }^{\mathrm{G}} \mathrm{The}$ sintered $\mathrm{SiC}$ materials exhibited large grain growth. tion observed in this study seems to be due to the $\mathrm{Al}$ solution from the additive $\mathrm{AlB}_{2}$. $4 \mathrm{H}-\mathrm{SiC}$ that contained $\mathrm{Al}$ atoms grew aspherically and was formed into rod- or plate-shaped grains during sintering.

\subsection{Grain shape and mechanical properties}

In general, grains in sintered materials have a round shape when they are made from $6 \mathrm{H}-\mathrm{SiC}$ powder. In this experiment, however, $\mathrm{SiC}$ grains had an elongated shape. This grain shape was expected to improve the mechanical properties. Microstructure and fracture toughness were then measured with an image analyzer and by the indentation fracture method, respectively. The results are summarized in Table 3. The table shows that the fracture toughness of $\mathrm{SiC}$ materials increased in proportion to the grain size and the aspect ratio. Clearly, $\mathrm{AlB}_{2}$ addition reduces the sintering temperature of $\mathrm{SiC}$ markedly, enhances aspherical grain growth, and thus contributes to the production of strong $\mathrm{SiC}$ materials.

Table 2. Polytype Contents in the Sintered SiC Specimens

\begin{tabular}{|c|c|c|c|c|}
\hline \multirow{2}{*}{$\begin{array}{l}\text { Sample } \\
\text { No. }\end{array}$} & \multirow[t]{2}{*}{ Sintering Temp. $\left({ }^{\circ} \mathrm{C}\right)$} & \multicolumn{3}{|c|}{ Polytype contents (\%) } \\
\hline & & $4 \mathrm{H}$ & $6 \mathrm{H}$ & $15 \mathrm{R}$ \\
\hline \multicolumn{2}{|c|}{$6 \mathrm{H}-$ Starting powder } & 2 & 98 & 0 \\
\hline SC-1a & 2000 & 4 & 92 & 4 \\
\hline $\mathrm{SC}-2 \mathrm{a}$ & 2000 & 9 & 86 & 5 \\
\hline $\mathrm{SC}-3 \mathrm{~b}$ & 2150 & 30 & 67 & 3 \\
\hline $\mathrm{SC}-3 \mathrm{c}$ & 1975 & 10 & 89 & 1 \\
\hline SC-3d & $1975^{*}$ & 7 & 93 & 0 \\
\hline $\mathrm{SC}-4 \mathrm{c}$ & 1975 & 4 & 85 & 11 \\
\hline
\end{tabular}

Holding time at the maximum temperature is $30 \mathrm{~min}$ or $* 0 \mathrm{~min}$.
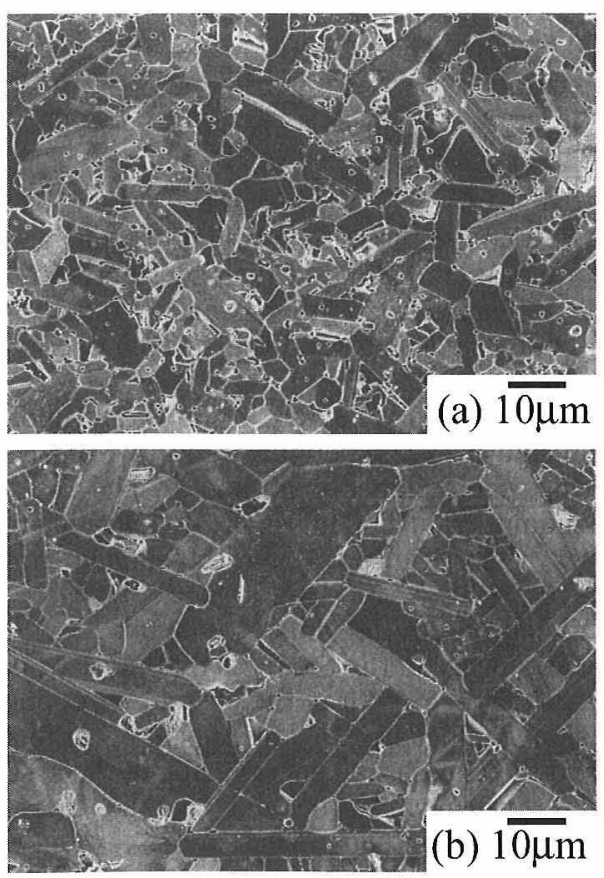

Fig. 5. Microstructures of the $\mathrm{SiC}$ material sintered from $\alpha(6 \mathrm{H})$ $\mathrm{SiC}$ powder with 2.7 mass\% $\mathrm{AlB}_{2}$ and 2 mass\% C, (a) at $1975^{\circ} \mathrm{C}$ and (b) at $2150^{\circ} \mathrm{C}$. 
Table 3. Grain Size, Aspect Ratio and Fracture Toughness of Sintered $\mathrm{SiC}$ Material

\begin{tabular}{cccc}
\hline $\begin{array}{c}\text { Sample } \\
\text { No. }\end{array}$ & $\begin{array}{c}\text { Grain size } \\
(\mu \mathrm{m})\end{array}$ & Aspect ratio & $\begin{array}{c}\mathrm{K}_{\mathrm{IC}} \text { by IF method } \\
\left(\mathrm{MPam}^{1 / 2}\right)\end{array}$ \\
\hline SC-1a & 1.7 & 1.6 & $3.6 \pm 0.3$ \\
SC-2a & 2.5 & 1.9 & $3.9 \pm 0.2$ \\
SC-3b & 6.1 & 2.6 & $4.3 \pm 0.2$ \\
SC-3c & 3.4 & 1.9 & $4.2 \pm 0.3$ \\
SC-3d & 3.1 & 1.8 & $4.1 \pm 0.2$ \\
SC-4c & 4.4 & 2.1 & (porous) \\
SC-B* & 1.3 & 1.7 & $3.0 \pm 0.2$ \\
\hline
\end{tabular}

*The reference specimen sintered with 0.3 mass $\%$ B and 2 mass $\% \mathrm{C}$

\section{New theory for sintering and grain growth}

4.1 Models for sintering and grain growth

When $\mathrm{SiC}$ powder compacts are heated at high temperatures, grains of $\mathrm{SiC}$ begin to sinter. During sintering, the surface area of the grains converts to the grain boundary area, and the total surface and grain boundary energy decreases. This decrease in energy is the driving force for sintering. The new sintering and grain growth theories developed from the total free energy theory ${ }^{7), 8)}$ are described in this section.

Two-sphere grain models for sintering and grain growth are proposed as shown in Fig. 6. In the models, two spherical grains of different size are in contact forming grain boundary. Sintering is defined as a process of reducing the distance between two grain centers and expanding grain boundary area with constant grain volumes, and grain growth is defined as a process where material is transported from a small grain to a large grain with a constant grain boundary area (Fig. 6).

The following non-dimensional parameters are defined for the calculation.

$$
\begin{aligned}
& R_{0}=\frac{r_{02}}{r_{01}}, R_{1}=\frac{r_{1}}{r_{01}}, R_{2}=\frac{r_{2}}{r_{02}}, \\
& X_{1}=\frac{x_{1}}{r_{1}}, X_{2}=\frac{x_{2}}{r_{2}}, \alpha=\frac{\varepsilon_{\mathrm{gb}}}{\varepsilon_{\mathrm{s}}}
\end{aligned}
$$

where $r_{01}$ and $r_{02}$ are the initial radii of grains 1 and $2, r_{1}, r_{2}$ and $x_{1}, x_{2}$ are grain radii and the distances between the grain center and the boundary of grains 1 and 2 , and $\varepsilon_{\mathrm{gb}}$ and $\varepsilon_{\mathrm{s}}$ are the grain boundary energy and the surface energy, respectively.

The grain size ratio is $0<R_{0} \leq 1$ and the ratio of the surface energy and the grain boundary energy is $0 \leq \alpha \leq 1$. During sintering, the distance of grains $X_{1}$ and $X_{2}$ decreases with expanding grain boundary. During grain growth, $R_{0}$ decreases by mass transport from the smaller grain to the larger grain.

\subsection{Driving energy for mass transport}

The basic concept of the theory is that mass transport for sintering and grain growth in the system is proportional to the diffusion coefficient, $D_{\mathrm{x}}$, the term of diffusion path $\left(a_{\mathrm{x}} / \lambda_{\mathrm{x}}\right)$ and the excess free energy, $\Delta G$, in the system. The rate of mass transport, $\mathrm{d} v / \mathrm{d} t$, and $\left(a_{\mathrm{x}} / \lambda_{\mathrm{x}}\right)$, therefore, are given by the following equations. ${ }^{30), 31)}$

$$
\frac{\mathrm{d} v}{\mathrm{~d} t}=D_{\mathrm{x}}\left(\frac{a_{\mathrm{x}}}{\lambda_{\mathrm{x}}}\right)\left\{1-\exp \left(\frac{-\Delta G}{R T}\right)\right\}
$$

(a)

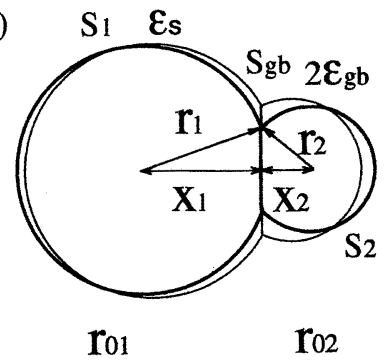

(b)

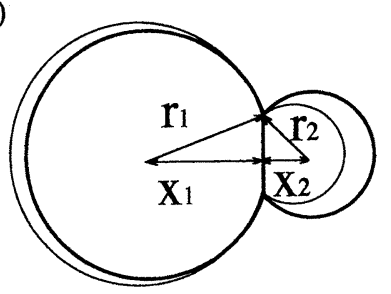

Fig. 6. Two-sphere models (a) for sintering and (b) for grain growth.

$$
\begin{aligned}
& \left(\frac{a_{\mathrm{x}}}{\lambda_{\mathrm{x}}}\right)^{-1}=\int_{\mathrm{sys}}\left(\frac{a_{\mathrm{m}}}{\lambda_{\mathrm{x}}}\right)^{-1} \mathrm{~d} v / \int_{\mathrm{sys}} \mathrm{d} v \\
& a_{\mathrm{m}}=\left(a_{\mathrm{i}} a_{0}\right)^{1 / 2}
\end{aligned}
$$

Where, $\left(a_{\mathrm{x}} / \lambda_{\mathrm{x}}\right)$ is given by the harmonic average of the mean diffusion area, $a_{\mathrm{m}}$, divided by the diffusion length, $\lambda_{\mathrm{x}}$, over the system, where $a_{\mathrm{m}}$ is defined as the mean cross-sectional area of mass flow from the area $a_{\mathrm{i}}$ to the outlet $a_{0} . R$ and $T$ are the gas constant and temperature, respectively.

4.3 Rate of grain shrinkage due to sintering

Referring to Fig. 6, the sum of surface and grain boundary energies, $\Psi$, which is normalized by the initial surface energy, is:

$$
\begin{aligned}
\Psi & =\frac{\left\{\varepsilon_{\mathrm{s}}\left(s_{1}+s_{2}\right)+2 \varepsilon_{\mathrm{gb}} s_{\mathrm{gb}}\right\}}{4 \pi \varepsilon_{\mathrm{s}}\left(r_{01}{ }^{2}+r_{02}{ }^{2}\right)} \\
& =\frac{R_{1}^{2}\left(1+X_{1}\right)+R_{0}^{2} R_{2}^{2}\left(1+X_{2}\right)+\alpha\left(1-X_{1}^{2}\right)}{2\left(1+R_{0}^{2}\right)}
\end{aligned}
$$

$\Psi$ decreases as $X_{1}$ and $X_{2}$ decrease until $\Psi$ reaches a minimum, $\Psi_{\min }$. The system is in an equilibrium state at $\Psi_{\min }$. The system in the present state has the excess energy, $\Delta \Psi$ $=\Psi-\Psi_{\min }$, which drives mass transport for sintering. $\Delta G_{\mathrm{s}}$ for the sintering in Eq. (2) for one mole is expressed as:

$$
\Delta G_{\mathrm{s}}=\frac{3 \varepsilon V_{\mathrm{m}}}{r_{01}} \Delta \Psi\left(1+R_{0}^{2}\right) /\left(1+R_{0}^{3}\right),
$$

where $V_{\mathrm{m}}$ is the mole volume.

The term of the diffusion path, $\left(a_{\mathrm{x}} / \lambda_{\mathrm{x}}\right)$, is obtained by integration of Eq. (3) with respect to the whole volume of the two-sphere model (Fig. 6). The calculation gives the following equations. ${ }^{8)}$

$$
\begin{aligned}
\left(\frac{a_{\mathrm{x}}}{\lambda_{\mathrm{x}}}\right) & =16 \pi r_{01} g_{\mathrm{d}} \\
g_{\mathrm{d}}= & \left(1+R_{0}^{3}\right)\left[\frac { R _ { 1 } ^ { 2 } } { ( 1 - X _ { 1 } ^ { 2 } ) ^ { 1 / 2 } } \left\{4\left(1-X_{1}^{2}\right)^{3 / 2}\right.\right. \\
& \left.+6 X_{1}^{2}\left(1-X_{1}^{2}\right)^{1 / 2}+6 X_{1} \arcsin X_{1}+3 \pi X_{1}\right\} \\
& +\frac{R_{0}^{2} R_{2}{ }^{2}}{\left(1-X_{2}\right)^{1 / 2}}\left\{4\left(1-X_{2}^{2}\right)^{3 / 2}+6 X_{2}^{2}\left(1-X_{2}^{2}\right)^{1 / 2}\right.
\end{aligned}
$$




$$
\left.\left.+6 X_{2} \arcsin X_{2}+3 \pi X_{2}\right\}\right]^{-1}
$$

It is also necessary to calculate the amount of mass required for sintering or for reducing $X_{1}$ and $X_{2}$. This is $\mathrm{d} v=$ $\left(\mathrm{d} X_{1}+\mathrm{d} X_{2}\right) \times($ the grain boundary area), and is expressed as:

$$
\frac{\mathrm{d} v}{\mathrm{~d} t}=-\frac{2 \pi r_{01}{ }^{3} R_{1}^{2}\left\{R_{1}\left(1-X_{1}\right)+R_{0} R_{2}\left(1-X_{2}\right)\right\}}{\left(2-X_{1}\right)} \frac{\mathrm{d} X_{1}}{\mathrm{~d} t} .
$$

From Eqs. (2), (4), (5)-(7), the shrinkage rate, $\mathrm{d} X_{1} / \mathrm{d} t$, for grain 1 due to sintering is calculated as follows.

$$
\begin{aligned}
\frac{\mathrm{d} X_{1}}{\mathrm{~d} t}= & -\left(\frac{3 \varepsilon_{\mathrm{s}} D_{\mathrm{x}} V_{\mathrm{m}}}{\pi R T}\right) \frac{8 \pi}{r_{01}{ }^{3}} \\
& \times \frac{\left(1+R_{0}{ }^{2}\right)\left(2-X_{1}\right) \Delta \Psi g_{\mathrm{d}}}{\left(1+R_{0}{ }^{3}\right) R_{1}{ }^{2}\left\{R_{1}\left(1-X_{1}\right)+R_{0} R_{2}\left(1-X_{2}\right)\right\}}
\end{aligned}
$$

$\mathrm{d} X_{2} / \mathrm{d} t$ for grain 2 is obtained by conversions of $X_{1}$ to $X_{2}$ and $X_{2}$ to $X_{1}, R_{1}$ to $R_{2}$ and $R_{2}$ to $R_{1}$, and $R_{0}$ to $1 / R_{0}$ in Eq. (8).

4.4 Growth rate of grains

The growth or shrinkage of two grains is driven by the excess surface energy. The excess energies, $\phi_{1}$ and $\phi_{2}$, for the grain growth of two grains 1 and 2 , respectively, are estimated by the difference in surface energies between grains 1 and 2 and the system. $\phi_{1}$ and $\phi_{2}$, and the excess energy, $\Delta G_{g}$, for the system are the mole average of $\phi_{1}(>0)$ and $-\phi_{2}(>0)$ and are given by the following equations, ${ }^{7), 8)}$

$$
\begin{aligned}
\phi_{1}= & \frac{\left\{\varepsilon_{\mathrm{s}}\left(s_{1}+s_{2}\right)+2 \varepsilon_{\mathrm{gb}} s_{\mathrm{gb}}\right\}}{\frac{4 \pi\left(r_{01}{ }^{3}+r_{02}{ }^{3}\right)}{V_{\mathrm{m}}}}-\frac{\left(\varepsilon_{\mathrm{s}} s_{1}+\varepsilon_{\mathrm{gb}} s_{\mathrm{gb}}\right)}{\frac{4 \pi r_{01}}{V_{\mathrm{m}}}} \\
\phi_{2}= & \frac{\left\{\varepsilon_{\mathrm{s}}\left(s_{1}+s_{2}\right)+2 \varepsilon_{\mathrm{gb}} s_{\mathrm{gb}}\right\}}{\frac{4 \pi\left(r_{01}{ }^{3}+r_{02}{ }^{3}\right)}{V_{\mathrm{m}}}}-\frac{\left(\varepsilon_{\mathrm{s}} s_{2}+\varepsilon_{\mathrm{gb}} s_{\mathrm{gb}}\right)}{\frac{4 \pi r_{02}}{V_{\mathrm{m}}}} \\
\Delta G_{\mathrm{g}}= & \frac{r_{01}{ }^{3}}{r_{01}{ }^{3}+r_{02}{ }^{3}} \phi_{1}-\frac{r_{02}{ }^{3}}{r_{01}{ }^{3}+r_{02}{ }^{3}} \phi_{2}=\frac{3 \varepsilon_{\mathrm{s}} V_{\mathrm{m}}}{r_{01}} f_{\mathrm{g}} \\
f_{\mathrm{g}}= & -\frac{1}{\left(1+R_{0}{ }^{3}\right)}\left[-\left\{\frac{1-R_{0}^{3}}{2\left(1+R_{0}^{3}\right)}\right\}\left\{R_{1}^{2}\left(1+X_{1}\right)\right.\right. \\
& \left.+R_{0}{ }^{2} R_{2}{ }^{2}\left(1+X_{2}\right)+\alpha R_{1}{ }^{2}\left(1-X_{1}^{2}\right)\right\} \\
& +\frac{R_{1}^{2}}{4}\left\{2\left(1+X_{1}\right)+\alpha\left(1-X_{1}^{2}\right)\right\} \\
& \left.-\frac{R_{0}^{2} R_{2}^{2}}{4}\left\{2\left(1+X_{2}\right)+\alpha\left(1-X_{2}^{2}\right)\right\}\right]
\end{aligned}
$$

where $\phi_{1}$ is positive and grain 1 grows, and $\phi_{2}$ is negative and the smaller grain 2 shrinks. The total mass required for grain growth is given as:

$$
\begin{aligned}
& \frac{\mathrm{d} v}{\mathrm{~d} t}=2 \times 4 r_{01}{ }^{2} \frac{\mathrm{d} r_{01}}{\mathrm{~d} t} \\
& 4 r_{01}{ }^{2} \frac{\mathrm{d} r_{01}}{\mathrm{~d} t}=-4 r_{02}{ }^{2} \frac{\mathrm{d} r_{02}}{\mathrm{~d} t}
\end{aligned}
$$

From Eqs. (2), (6), (9) and (10), the growth rate for grain 1 is calculated using Eq. (11).

$$
\frac{1}{r_{01}} \frac{\mathrm{d} r_{01}}{\mathrm{~d} t}=\left(\frac{3 \varepsilon_{\mathrm{s}} D_{\mathrm{x}} V_{\mathrm{m}}}{\pi R T}\right) \frac{2 \pi}{r_{01}{ }^{3}} f_{\mathrm{g}} g_{\mathrm{d}}
$$

The growth rate for grain 2 is obtained using Eqs. (10) and
(11).

\subsection{Calculations of sintering shrinkage and grain growth}

Sintering and grain growth are assumed to take place simultaneously. The sintering shrinkage, $\mathrm{d} X_{1}$ and $\mathrm{d} X_{2}$, and the changes of grain radii, $\mathrm{d} r_{01}$ and $\mathrm{d} r_{02}$, were calculated from Eqs. (8) and (11) for the infinitesimal time, $\mathrm{d} t$. They were sequentially summed up. The calculation began at $X_{1}$ and $X_{2}=1 \quad($ time $=0)$, and continued until $X_{2}$ reached 0 . Some of the results are shown in Fig. 7. The sintering behaviors of two grains in Fig. 7 are represented as a function of $\alpha$ in Fig. 8. In Fig. 7 the changes in $X_{1}$ and $r_{02}$ are plotted under the conditions, for example, of constant $\alpha(=0.5)$ with varying $R_{0}$ or constant $R_{0}(=0.5)$ with varying $\alpha$.

4.6 Sintering and grain growth behavior of two grains

The calculations of sintering behavior (Figs. 7 and 8) clearly revealed the effects of the grain boundary energy. When the ratio of the grain boundary to surface energy, $\alpha$,
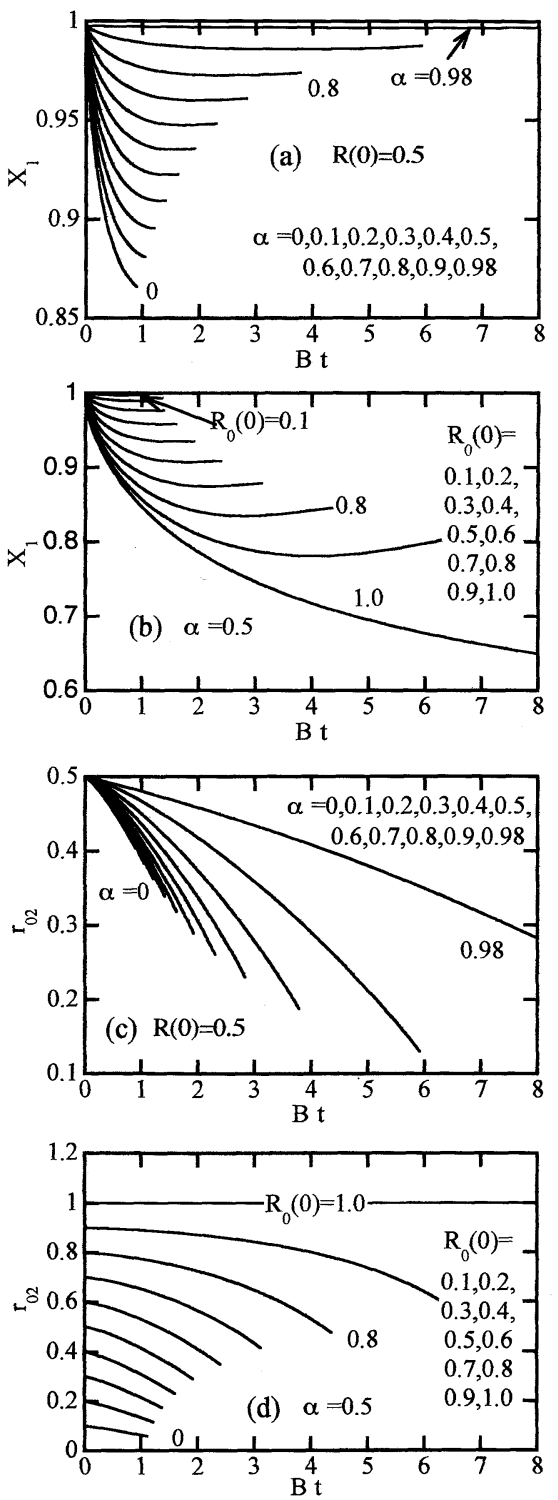

Fig. 7. Changes of $X_{1}$ and $r_{02}$ with time $\mathrm{Bt}$. $\mathrm{B}\left(=3 \varepsilon_{\mathrm{s}} D_{\mathrm{x}} V_{\mathrm{m}} / \pi R T\right)$ is a normalizing factor. The initial grain size ratio, $R(0)$, was held constant at 0.5 while the ratio of grain boundary energy to surface energy, $\alpha$, was varied from 0 to 0.98 in (a) and (c). $\alpha$ was held constant at 0.5 while $R_{0}(0)$ was varied from 0.1 to 1 in (b) and (d). 


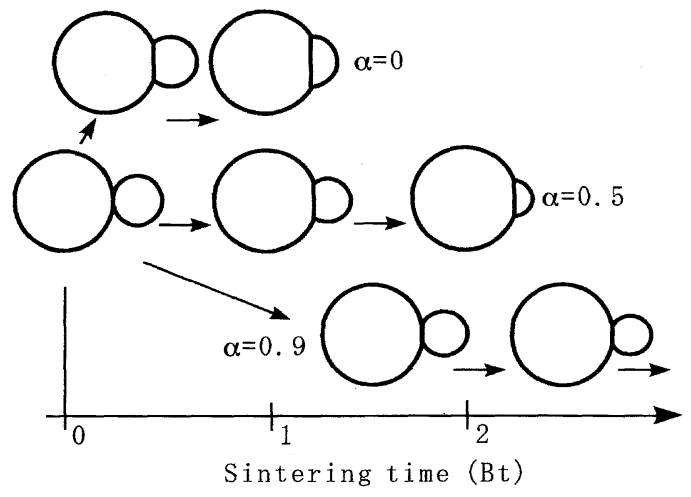

Fig. 8. Schematics of sintering behavior of two joining grains. The sintering (grain boundary expansion) rate became faster and the grain shrinkage rate of the smaller grain became slower as $\alpha$ increased from 0 to 0.9 .

was small, $X_{1}$ rapidly reached 0 , while $r_{02}$ did not decrease significantly. Two grains coalesced in a short period of time, but grain growth was not fast. This means that a powder can be sintered very easily when its grain boundary energy is small. When $\alpha$ was nearly $1, X_{1}$ did not change remarkably, and almost retained its initial value of 1 . This means that a powder with high grain boundary energy can sinter negligibly. There was also a tendency for grain growth to take place dominantly when the size ratio of two grains $\left(R_{0}\right)$ was small. In this case, the grain boundary did not expand markedly and sintering proceeded slowly.

The calculations performed here demonstrate that the smaller the grain boundary energy and the smaller the difference in grain size, the faster the sintering occurs. It is therefore suggested that the pure $\mathrm{SiC}$ powder hardly sinters, because $\mathrm{SiC}$ has a highly covalent bonding nature and the grain boundary energy is almost as large as the surface energy. ${ }^{32), 33)}$ The additives, such as $\mathrm{B}$ and $\mathrm{C}$, or $\mathrm{AlB}_{2}$ and $\mathrm{C}$, are necessary for decreasing the grain boundary energy. Fine $\mathrm{SiC}$ powders with uniform grain distribution and suitable additives sinter readily, as shown in the previous sections 2 and 3 .

\section{Summary}

In this paper, the three important aspects of $\mathrm{SiC}$ materials, that is, the powder synthesis, the sintering process, and the theory of sintering and grain growth are reviewed. They are summarized as follows.

(1) $\mathrm{SiC}$ precursors were derived from the liquid materials of silicon-tetraethoxide and phenolic resin. Homogeneous mixing of $\mathrm{SiO}_{2}$ and $\mathrm{C}$ could be achieved in the precursor. The pure $\mathrm{SiC}$ powders without residual carbon were obtained by carbothermic reduction of the precursors. SiC powders were of the single-phase $\beta$ (3C) type, and sintered with the addition of carbon and a small amount of $\mathrm{B}$.

(2) The low-temperature sintering of $\mathrm{SiC}$ powder was developed using $\mathrm{AlB}_{2}$ and $\mathrm{C}$ additives. These additives could sinter $\mathrm{SiC}$ powder at around $1900^{\circ} \mathrm{C}$, and promoted elongation of $\alpha$-SiC grains during sintering. $\mathrm{Al}$ atoms from the additive appear to have dissolved into $\mathrm{SiC}$ and partly transformed $6 \mathrm{H}-\mathrm{SiC}$ into $4 \mathrm{H}-\mathrm{SiC}$. This transformation caused anisotropic grain growth. The fracture toughness of the sintered $\mathrm{SiC}$ materials increased as the aspect ratio and the size of grains increased.

(3) New models and theory for sintering and grain growth were proposed. The theory assumed that the total free energy on the surface and grain boundary of grains drove mass transport. The rate equations for sintering and grain growth were derived from the theory, and the sintering behavior involved in joining two grains was simulated. It is found that the grain boundary energy, which was dependent on the additives used, was important for sintering of $\mathrm{SiC}$, and that low grain boundary energy was necessary for stimulation of sintering and suppression of grain growth.

\section{References}

1) "Silicon Carbide Ceramics-1," Ed. by Sōmiya, S. and Inomata, Y., Elsevier Appl. Sci., London (1991) pp. 1-288.

2) “Advanced Silicon Carbide Ceramics," Ed. by Suzuki, H., Iseki, T. and Tanaka, H., Uchida Rokakuho, Tokyo (2001) pp. 1-350 [in Japanese].

3) Tanaka, H. and Kurachi, Y., Ceramics International, 14, 109-15 (1988).

4) Tanaka, H., Jin, K. and Hirota, K., J. Ceram. Soc. Japan, 98, 607-10 (1990) [in Japanese].

5) Tanaka, H. and Zhou, Y., J. Mater. Res., 14, 518-22 (1999).

6) Zhou, Y., Tanaka, H., Otani, S. and Bando, Y., J. Am. Ceram. Soc., 82, 1959-64 (1999).

7) Tanaka, H., J. Ceram. Soc. Japan, 103, 138-43 (1995) [in Japanese].

8) Tanaka, H., J. Ceram. Soc. Japan, 105, 294-98 (1997).

9) Prochazka, S., "Special Ceramics 6," Ed. by Popper, P., Brit. Ceram. Associ., Stoke on Trent, UK (1975) pp. 171-81.

10) Dutta, S., J. Am. Ceram. Soc., 68, C269-70 (1985).

11) Ghosh, A., Jenkins, M. G., White, K. W., Kobayashi, A. S. and Bradt, R. C., J. Am. Ceram. Soc., 72, 242-47 (1989).

12) Tsuruta, H., Masuda, M., Soma, T. and Matsui, M., J. Am. Ceram. Soc., 73, 1714-18 (1990).

13) Tanaka, H., Inomata, Y., Tsukuda, K. and Hagimura, A., J. Ceram. Soc. Japan, 92, 461-65 (1984) [in Japanese].

14) Tanaka, H., Inomata, Y., Hara, K. and Hasegawa, H., $J$. Mater. Sci. Lett., 4, 315-17 (1985).

15) Böcker, W. and Hausner, H., Powder Metal. Int., 10, 87-89 (1978).

16) Suzuki, H. and Hase, T., J. Am. Ceram. Soc., 63, 349-50 (1980).

17) Gu, H., Shinoda, Y. and Wakai, F., J. Am. Ceram. Soc., 82, 469-72 (1999).

18) Frenkel, J., J. Phys., 9, 385-91 (1945).

19) Kuczynski, G. C., J. Appl. Phys., 21, 632-36 (1950).

20) Kingery, W. D., J. Am. Ceram. Soc., 37, 42-45 (1954).

21) Coble, R. L., J. Appl. Phys., 32, 787-99 (1961).

22) Ashby, M. F., Acta Metal., 22, 275-89 (1974).

23) Kingery, W. D., Bowen, H. K. and Uhlmann, D. R., "Introduction to Ceramics," John Wiley \& Sons, New York (1976) pp. 448-515.

24) German, R. M., "Sintering Theory and Practice," John Wiley \& Sons, New York (1996) pp. 1-550.

25) Zener, C., J. Appl. Phys., 20, 950-53 (1949).

26) Burk, J. E. and Turnbull, D., "Progress in Metal Physics 3," Ed. by Chalmers, B., Pergamon Press, London (1952) pp. 220-92.

27) Lifshitz, I. M. and Slyozov V. V., J. Phys. Chem.. Solids, 19, 35-50 (1961).

28) Wagner, V. C., Zeitschrift fuer Electrochem., 65, 581-91 (1961).

29) Inomata, Y., Tanaka, H., Inoue, Z. and Kawabata, H., J. Ceram. Soc. Japan, 88, 353-55 (1980).

30) Inomata, Y., J. Ceram. Soc. Japan, 90, 527-31 (1982) [in Japanese].

31) Tanaka, H., J. Ceram. Soc. Japan, 104, 253-58 (1996).

32) Inomata, Y., Uemura, Y., Inoue, Z. and Tanaka, H., J. Ceram. Soc. Japan, 88, 628-33 (1980) [in Japanese].

33) Uemura, Y., Inomata, Y. and Inoue, Z., J. Mater. Sci., 16, 2333-35 (1981). 


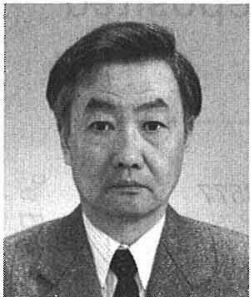

Hidehiko Tanaka graduated from the Department of Inorganic Material at Tokyo Institute of Technology in 1971. He obtained his M. S. and Ph. D. degrees at the same institute in 1973 and 1977, respectively. He was a part-time lecturer in the Department of Physics at Musashi Institute of Technology in 1977, and took a position in National Institute for Research in Inorganic Materials in 1977. He worked as an invited researcher at the Max Planck Institute for Metals Research, Germany, in 1984-85 and at the National Institute of Applied Science of Lyon, France, in 1986. He received the CerSJ Awards for Advancement in Ceramic Science and Technology from the Ceramic Society of Japan in 1981. His current research interests include the development of $\mathrm{SiC}$ materials and new sintering theory. 